\title{
An Analysis of Operating Parameters in an Environment with High Heat Load
}

\author{
Zuzana Kolková1 ${ }^{1}$ Peter Hrabovský1 ${ }^{1}$, Jozef Matušov ${ }^{1}$, Pavol Belány ${ }^{1}$ \\ ${ }^{1}$ University of Žilina, Research centre \\ Univerzitná 8215/1, Žilina, Slovakia \\ zuzana.kolkova@uniza.sk; peter.hrabovsky@uniza.sk; jozef.matusov@uniza.sk; pavol.belany@uniza.sk
}

\begin{abstract}
Workers in the kitchen are often exposed to excessive heat. This increased load arises from the various appliances and equipment used to prepare food. In most cases, workers are older and it is therefore important to ensure the quality of the working environment. This paper analyses the working conditions in the catering facility, defines the individual parameters and describes in detail the environment in which workers spend their working time. Each of the parameters defines the state of the environment. Measurements were performed in real conditions on working days. The period was summer, when the heat load was higher. The aim of the measurements was to identify critical points and to propose measures to improve working conditions to ensure thermal comfort. Measuring the level of thermal comfort and indoor air quality in workplaces allows the optimization of indoor climate parameters and reduces the risk of staff absence due to disease. Measuring the level of thermal comfort and indoor air quality also contributes to improving staff performance.
\end{abstract}

Keywords: human, health, temperature, comfort, thermal, heat

\section{Introduction}

Ensuring thermal comfort in kitchens is a very demanding process and an often solved problem. The research is currently divided into two groups. The first group consists of catering facilities that have air conditioning and the second group of kitchens without an air conditioning system. In the first case, there are problems with local discomfort. The layout of individual equipment and devices for food preparation is mainly static and the working position of workers is defined by this layout. There is a risk of drafts from air conditioners due to increased air velocities in the room. In the case of catering facilities without air conditioning, there is an increased heat load due to insufficient ventilation and an increase in the internal temperature due to the food preparation process.

Thermal comfort has been evaluated in more than 100 commercial kitchens in the United States by Simone A., Olesen, B.W., Stoops and A.W. Watkins [1]. Physical measurements have revealed that there is a wide range of kitchens where employees are exposed to a hot environment. In the US, the restaurant industry is the second largest private sector employer with a workforce. Job growth is expected in the next period. Research in China shows [2] that in the average household a person spends an average of 3.6 hours a day preparing food [3,4], and therefore it is important to ensure a healthy and comfortable environment. Research has shown that there is a link between fumes from the kitchen and the risk of lung cancer, mainly due to insufficient ventilation [5, 6, 7]. In India, Alam and colleagues have focused on research into thermal comfort in railway kitchens, where they have studied the effect of air conditioning on the thermal feeling of employees [8], as well as research in domestic kitchens [9]. Kitchen ventilation was investigated by Schrock, Beardslee and Sun [10], where they focused on the appropriate arrangement of systems and kitchen design to ensure optimal thermal comfort.

Current regulations may be insufficient for the analysis of thermal comfort in kitchens. The main influence on the thermal comfort is the radiant heat generated during the operation of the kitchen. Problems are also caused by the location of employees' work zones, the layout of individual equipment and systems. The number of employees in the kitchen is also an important factor.

\section{Human and thermal comfort}

Our health, comfort and performance are affected by the internal thermal environment. Responses and reactions have been the subject of many years of extensive research. The results are part of several methods for determining the state of the indoor environment and its design. The analysis of the thermal balance of the human body is the main research goal. This analysis influences methods for research into the overall thermal state of the body in the field of comfort but also in evaluating 
the effects of heat and cold on humans. Equation (1) describes the heat gain of the human body, which is balanced by heat loss under cold to neutral conditions.

$$
S=M-W-C-R-E_{s k}-C_{r e s}-E_{r e s}-K
$$

Where S - Heat storage in the human body $\left(\mathrm{W} / \mathrm{m}^{2}\right), \mathrm{M}$ - Metabolic heat production, $\mathrm{W}$ - external work, C - heat loss by convection; $\mathrm{R}$ - Heat loss by radiation; $\mathrm{E}_{\mathrm{sk}}$ - Evaporative heat loss from skin; $\mathrm{C}_{\mathrm{res}}-$ Convective heat loss from respiration; $\mathrm{E}_{\text {res }}$ - Evaporative heat loss from respiration; $\mathrm{K}$ - Heat loss by conduction [11, 12].

The four environmental factors influencing this heat balance are: air and mean radiant temperature $\left({ }^{\circ} \mathrm{C}\right)$, air velocity $(\mathrm{m} / \mathrm{s})$, and partial water vapor pressure $(\mathrm{Pa})$. The two personal variables are metabolic heat production due to the activity level $\left(\mathrm{W} / \mathrm{m}^{2}\right.$ or MET) and the thermal resistance of clothing $\left(\mathrm{CLO}\right.$ or $\left.\mathrm{m}^{2} \mathrm{~K} / \mathrm{W}\right)$. If the heat accumulation is zero, the combined action of these parameters must be in equilibrium. If the environment is too cold, negative heat storage occurs. The average temperature of the human body must be within a certain range and the heat losses due to sweating must be low. These conditions ensure thermal comfort. The temperature range is $36-38^{\circ} \mathrm{C}$. The human body has an effective thermoregulatory system. The main thermostat is the hypothalamus. The thermal environment for each person cannot be determined due to individual differences and preferences. The presence of occupants who will be dissatisfied will always be. It is possible to achieve a state that will suit a certain percentage of the population. Every occupant can be acceptably satisfied or satisfaction with the environment will increase. However, occupants must have sufficient personal control (choice and form of clothing, setting the air speed in the room, setting the temperature individually for certain offices, place of work and level of activity). It is possible to achieve thermal comfort in some cases with higher heat quality (less dissatisfied occupants) or lower (more dissatisfied occupants) [12, 13].

Thermal comfort is described as the state of mind. This state expresses satisfaction with the thermal environment. A definition was quickly comprehended. On the other side it is hard to capture in physical parameters [14]. Thermal comfort values are defined and described in international standards such as ISO EN 7730 [15] and ASHRAE Standard $55[16]$.

\section{Methods}

To ensure thermal comfort, it is necessary to consider all 6 factors: clothing insulation, metabolic rate, air and radiant temperature, air velocity and humidity. The first two factors take into account the human and other conditions of the working environment. The measurements for standing occupants are made at the $0.1,1.1$, and $1.7 \mathrm{~m}$ above the floor. Operative temperature is measured at the $0.6 \mathrm{~m}$ for seated occupants and the $1.1 \mathrm{~m}$ above the floor for standing occupants. Measurement conditions may be changed if the location of the instruments and equipment of the premises obstructs the view of important sources of radiation.

The valid standard STN EN ISO 7730 Ergonomics of the thermal environment and the standard ASHRAE 55-2017 stipulate a method for predicting the mean thermal sensation (PMV) and the expected degree of discomfort (thermal dissatisfaction - PPD) of people exposed to a mild thermal environment. According to the measured parameters of the thermal-humidity microclimate defined in regulation 99/2016 in Slovak Republic it is possible to predict a person's thermal sensation by calculating a mean heat sensation (PMV). The Dissatisfaction Percentage (PPD) prediction provides information about thermal discomfort or dissatisfaction by predicting the percentage of people who are likely to feel too hot or too cold in a given environment. Unwanted local cooling or body heating can also be the cause of thermal discomfort. The most common local discomfort is drafts, defined as the movement of air causing local cooling of the body [17].

A modern device is used for measuring thermal comfort in the workplace. ComfortSense is a multichannel device for measurement air temperature and velocity, operative temperature and humidity. It calculates statistical values Draught rate (DR) in accordance with ISO 7730, Predicted Mean Vote (PMV) in accordance with ASHRAE 55 and ISO 7730 and Predicted Percentage Dissatisfied (PPD) in accordance with ASHRAE 55 and ISO 7730. ComfortSense is used for many applications in all sectors. It provides solutions for building research, passengers and occupants comfort, 
research, development and testing of heating and ventilation equipment, research in the automotive and aviation industries.

A main frame with input channels for up to 16 probes consist the ComfortSense system. The air velocity and temperature temperature probes are omnidirectional. The device can also be used for large test rooms thanks to robust probes and cable. cable. An omnidirectional thin-film sensor for measuring air velocity and a small fast-response thermistor for measuring air air temperature are a design solution of the draught probe. DantecComfort Sense also includes the manikin version. It has flexible cables that at-tach to the probe tip and is compact. It is suitable for placement on manikin for passenger comfort research. Velocity range is 0.05 to $5 \mathrm{~m} / \mathrm{s}$, indicates up to $10 \mathrm{~m} / \mathrm{s}$ (accuracy $0-1 \mathrm{~m} / \mathrm{s}: \pm 2 \%, 1-5 \mathrm{~m} / \mathrm{s}: \pm 5 \%, 5-10 \mathrm{~m} / \mathrm{s}: \pm 10 \mathrm{~m} / \mathrm{s}$ ) and temperature is -20 to $80^{\circ} \mathrm{C}$ (accuracy at velocities above $0.1 \mathrm{~m} / \mathrm{s}: 0-45^{\circ} \mathrm{C}- \pm 0,2 \mathrm{~K}$ ) for both types. Robust velocity and temperature probe have velocity range 0.1 to $30 \mathrm{~m} / \mathrm{s}$. Humidity range is $0-100 \%$ of relative humidity (accuracy: $0-10^{\circ} \mathrm{C}$ is $+2 \% \mathrm{RH}, 10-30^{\circ} \mathrm{C}$ is $+1.5 \% \mathrm{RH}, 30-45^{\circ} \mathrm{C}$ is $+2 \% \mathrm{RH}$ ). Dantec contains operative temperature probe. The sensor element simulates a standing person as well as a sitting person. Standing person is in position vertical. Sitting person is tilted $30^{\circ} \mathrm{C}$ from vertical and a reclining person when probe is in the horizontal position. Temperature range is $0-45^{\circ} \mathrm{C}$ (accuracy: 0 $10^{\circ} \mathrm{C}$ is $\pm 0,5 \mathrm{~K}, 10-40^{\circ} \mathrm{C}$ is $\pm 0.2 \mathrm{~K}, 40-45^{\circ} \mathrm{C}$ is $\left.\pm 0.5 \mathrm{~K}\right)$ [18].

The value of clothing insulation determines the resistance to appreciable heat transfer depending on the garment used, expressed in units of duty (a unit for quantifying the insulation provided by the garment and its components). ( 1 CLO $=0.155$ $\mathrm{m} 2{ }^{\circ} \mathrm{C} / \mathrm{W}$ ) for all garment components. The insulation of clothing for kitchen work was chosen to be 0.5 CLO.

The level of human activity is a measure of the transformation of chemical energy into thermal and mechanical work by the metabolic activities of individuals in MET units. $1 \mathrm{MET}=58.2 \mathrm{~W} \cdot \mathrm{m}^{-2}$, which represents the energy produced per unit area of skin of the average person sitting at rest. According to regulation 99/2016, work in the food industry is classified in class $1 \mathrm{c}$, which represents energy expenditure in the range from 106 to $130 \mathrm{~W} \cdot \mathrm{m}^{-2}$. The value of $2.5 \mathrm{MET}$ was chosen for the level of human activity for the performed work activity in catering facilities, depending on the calculation possibilities of the ComfortSense program.

\section{Experimental setup}

The kitchen is located in the basement of the building. There are no windows to the outside. The room has an L-shaped floor plan. The room is divided into two parts. In the first part, food is heated and dispensed, and in the second room there is a dishwasher. There is an air conditioning system in the room, which is used to extract steam from the food dispensing area and from the washroom without a supply of fresh air. There are two workers working in the room. In terms of environmental assessment for both workers, the L-shaped room was divided into two assessed areas, namely the washroom and the kitchen (Fig. 1). When evaluating the operating conditions, the results are determined for each location separately.
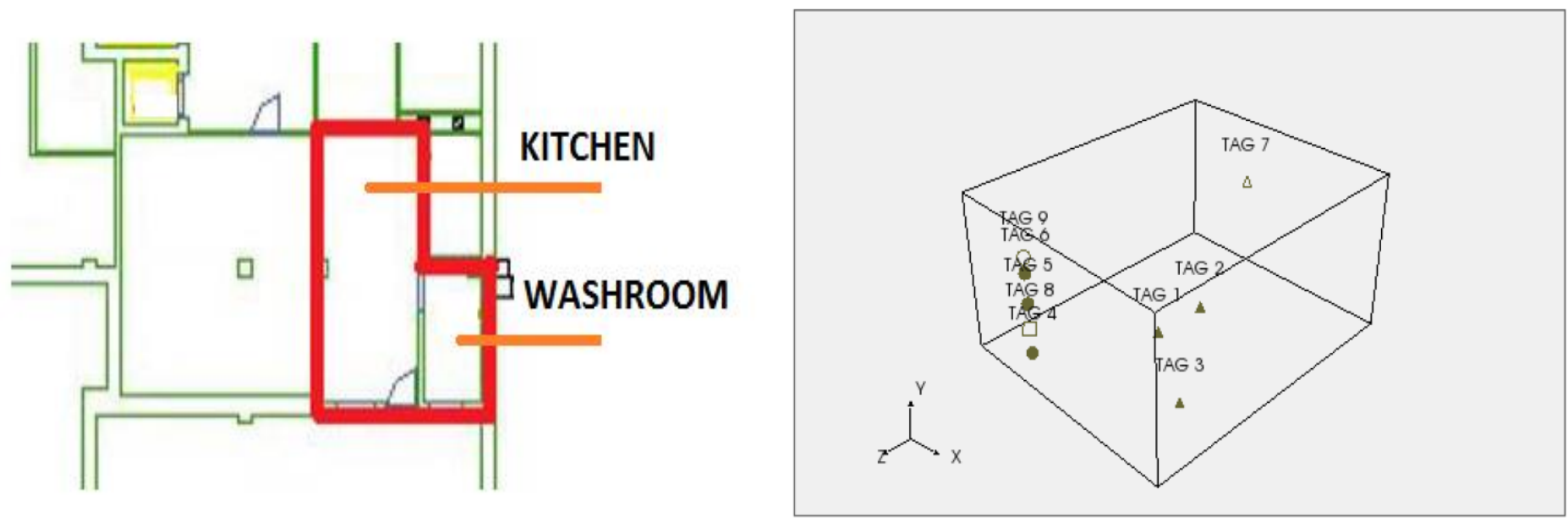

Fig. 1: The position of the kitchen and the location of the probes in the program Dantec ComfortSense 
The working position of female workers is standing. For this reason, head and leg body levels were assessed for both jobs. This measurement was also influenced by the capabilities of the Dantec instrument. The measuring probes were placed in the working space (Fig. 2) so that they best capture the working position of the workers and at the same time did not interfere with their work. These positions were defined as the most frequent job positions. Measuring device was not possible to place in the middle of the room. The kitchen staff is the same and for this reason the research of satisfaction with the thermal environment was carried out by a simple questionnaire. Both workers felt excessive heat and felt uncomfortable. The measurement was long-term and was performed in the summer.
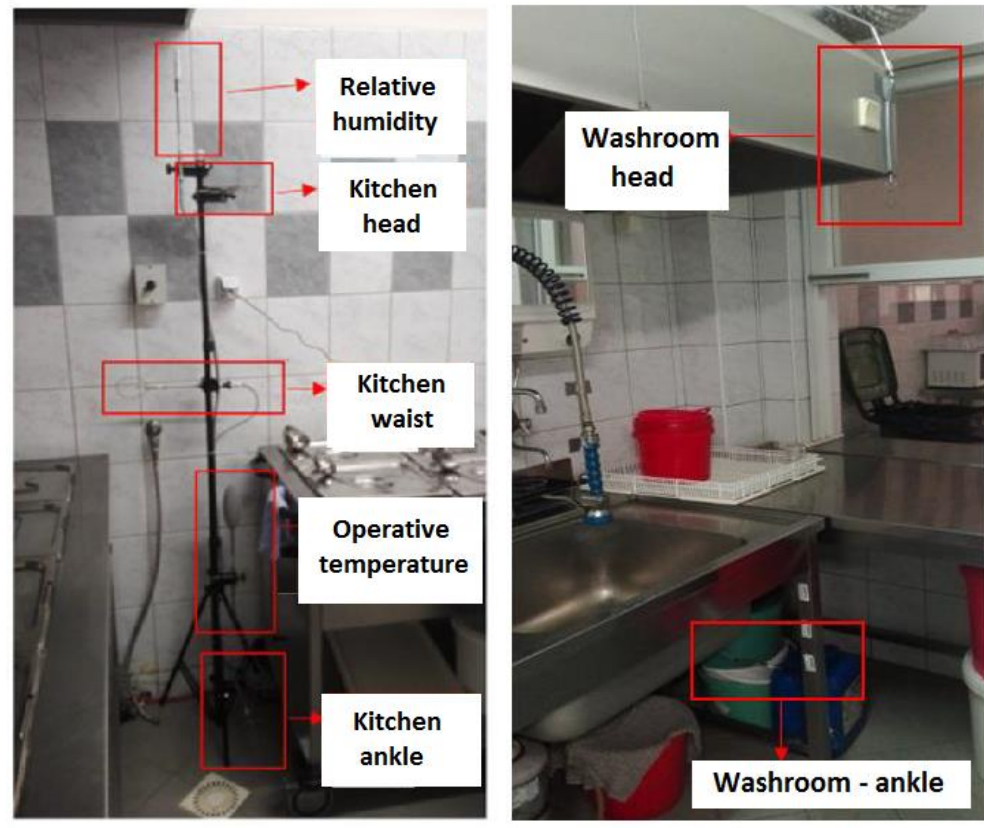

Fig. 2: The location of the probes in the kitchen and washroom

\section{Results}

The measurement of operating parameters of the working environment and thermal comfort took place in September. The outdoor temperature was in the range of $28 \pm 2^{\circ} \mathrm{C}$. The month of September was chosen due to the operation of the kitchen, when after the summer period, normal operation begins. The operation of the kitchen in the summer months is affected by the holidays of employees. The operating temperature and relative humidity are evaluated for both rooms together (Fig. 3). It is clear from the flow charts of the operating temperature measurement that the temperature exceeds the recommended value $26^{\circ} \mathrm{C}$. Over time, the operating temperature increases. The kitchen opens at 10:30 and the temperatures in this area have been high since the beginning of working hours. One reason is the presence of food heaters that keep it warm. After 11 o'clock, the presence of other employees increases, which increases the use of appliances in the kitchen and increases the operating temperature in the room. The kitchen room and the dishwasher are connected by a construction opening and interact with each other. In the measurement of relative humidity, a higher concentration is proven, which is mainly caused by fumes from food preparation and dishwasher operation. Cooling in these rooms is not forced. There is only natural convection into the dining area through the building opening. The door is not here. Fresh air is supplied to the rooms via an air ventilation system. It is not possible to open windows in these spaces. Due to all operating conditions and equipment settings, there are not many options for changing workplace conditions. The simplest and fastest solution to operate is to set the supply of fresh air from the air conditioning system and change the performance of the extractor hood. The following results are for normal operation, when the hood power is $50 \%$ and the air change is 0.8 times per hour. 

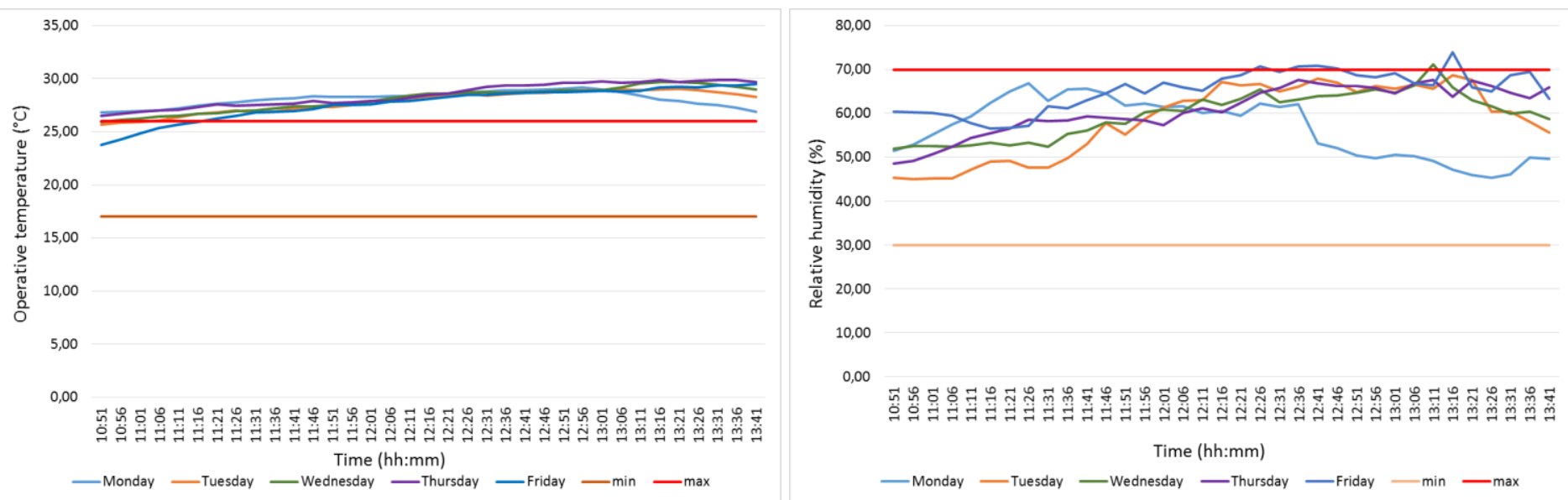

Fig. 3: Operative temperature and relative humidity in the kitchen

Operating temperature and relative humidity were evaluated for the kitchen and washroom. Other parameters are evaluated with respect to the job position of workers. The results of the measurements show that a worker working in the kitchen is more bothered by drafts than a worker in the washroom. Excessive drafts occur at the level of the head. Other positions are at an acceptable level. The cause may be in the open entrance door to the building, when a draft is created in the access corridor and then passes into the kitchen area. The washroom is protected by a building structure against the influence of this draft. From the main room there is only a small opening through which dishes are fed into the washroom (Fig. 4-left). The maximum air velocity is $0.2 \mathrm{~m} / \mathrm{s}$ and draught rate below $20 \%$. Fig. 4-right shows the formation of local discomfort caused by the temperature difference between the legs and the head.
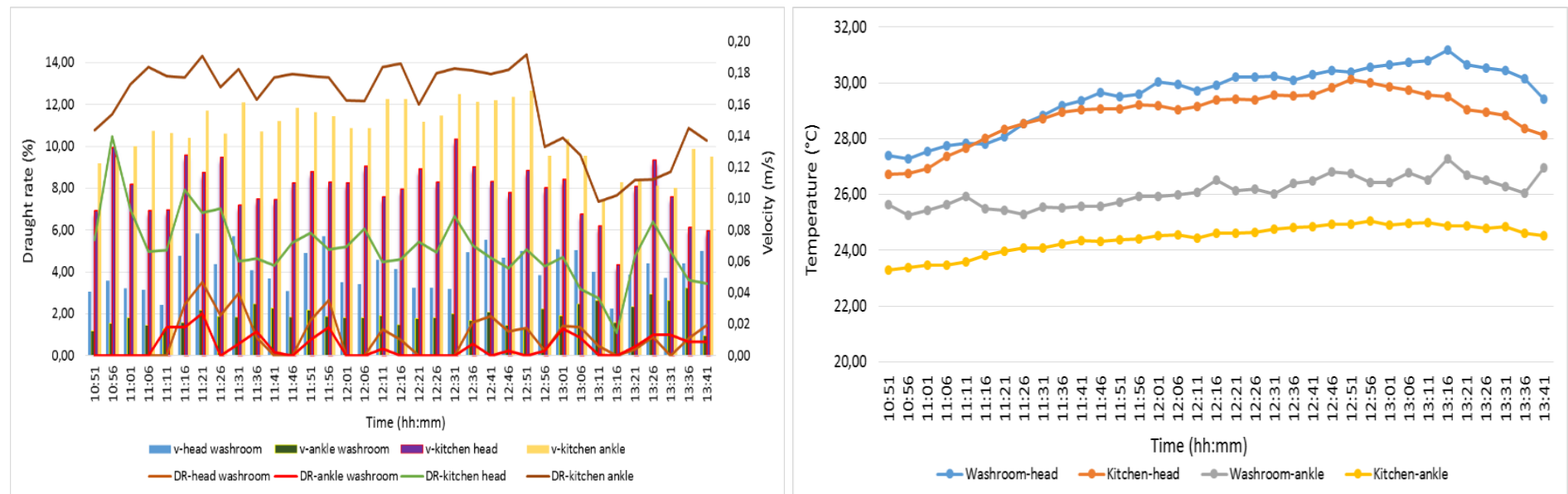

Fig. 4: Air velocity and draught rate, temperature difference between ankles and head

ISO Standard EN 7730 recommends using the PMV-index only in the interval \pm 2 . The PMV factor contains all the environmental parameters that are needed to ensure optimal conditions. If the PMV factor is in the range from -0.5 to +0.5 , thermal comfort in the space is achieved. The PMV factor is evaluated using a Dantec ComfortSense instrument. The software evaluates the PMV factor based on the measured data from all probes and data on the activity performed and the clothing worn. This system provides PMV measurements for all parts of the human body according to the measurement settings (Fig. 5). The measurement of PMV and PPD parameters reaches values for PMV above 1.5 and for PPD above 55\%. When evaluating the PMV parameter, we are at the heat level and there is a high percentage of dissatisfied. 


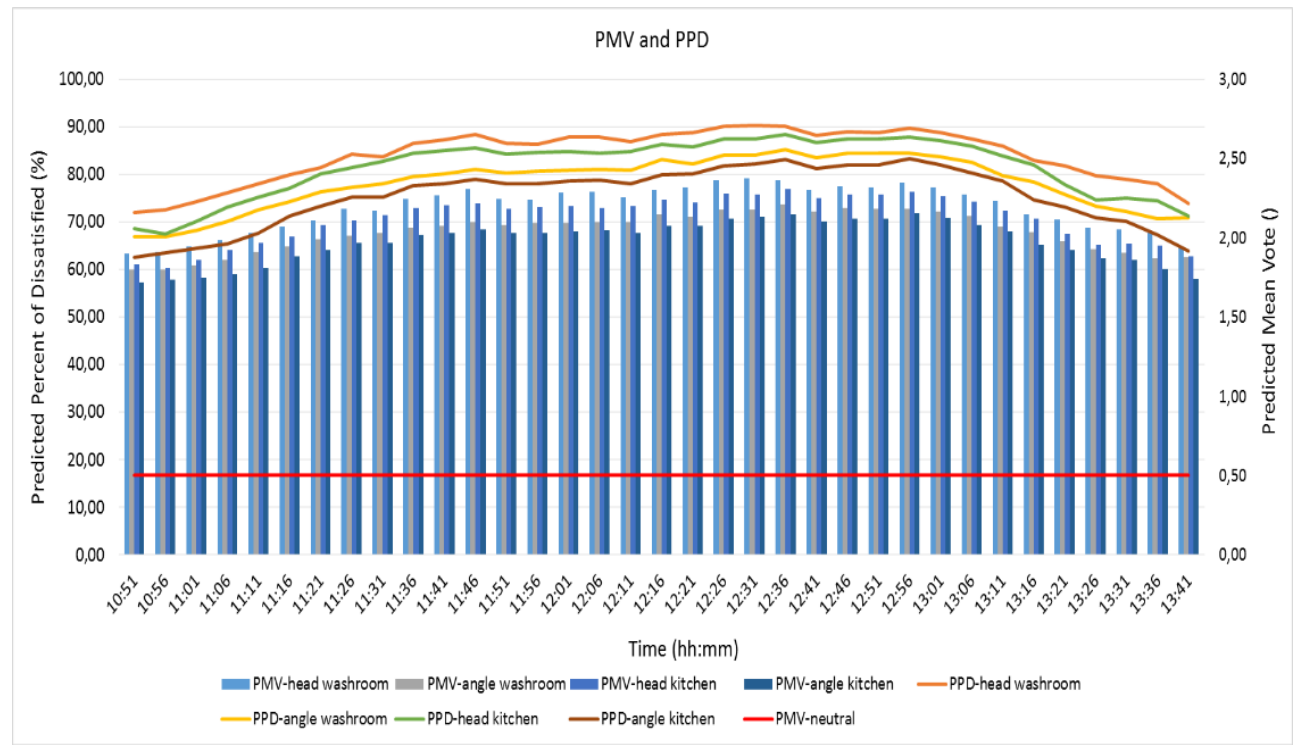

Fig. 5: Parameters PMV and PPD

Dissatisfaction of employees was also found by the result of measurements and working conditions were found from interviews with employees. In the first step, the simplest and most operational solutions were identified. The change concerns the setting of the fresh air supply and the hood power. The air exchange was set to the maximum of the technology and ie. 1 time per hour and the power of the extractor hood to the maximum - 100\%. The position of the Dantec device remained the same. The measurements were always performed in the presence of the same employees. Fig. 6 on the left shows the new results from the operative temperature measurement and on the left are the results for relative humidity. With the new setting, we managed to reach the values of the operating temperature within the set limit for a certain time. The temperature increased during working hours.
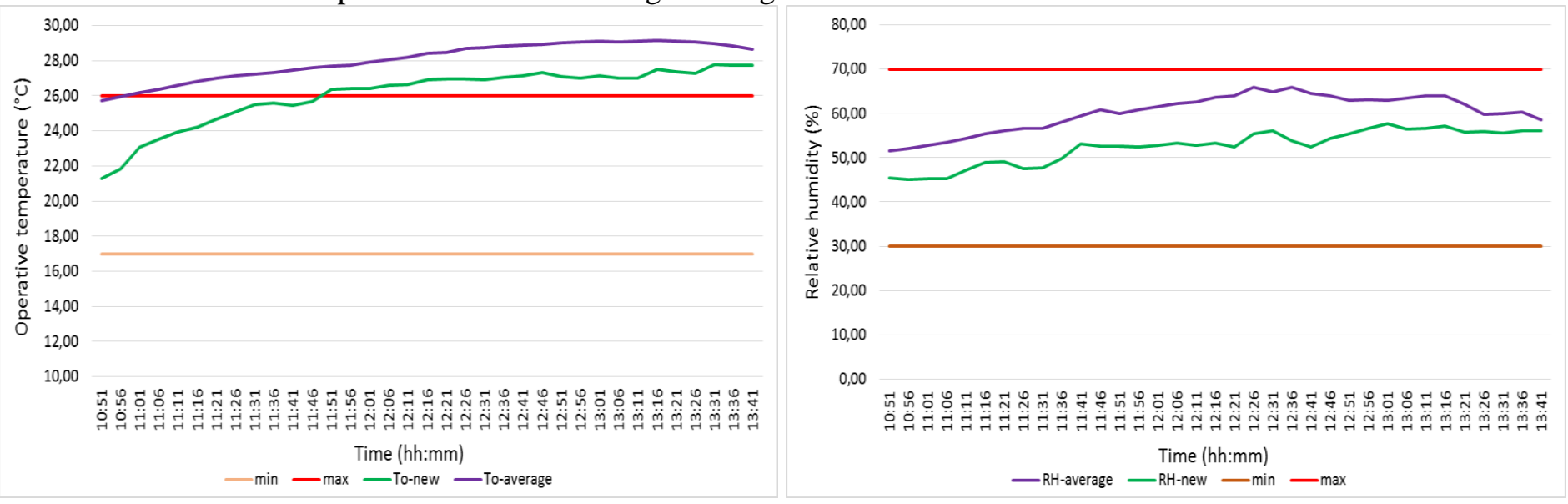

Fig. 6: Operative temperature and relative humidity in the kitchen - new settings

The low value at the beginning of the measurement is due to the fact that it is the beginning of the working hours of the operation and the space was ventilated and cooled from the night time. The operation of the devices has just started and it took some time for the temperature to rise to a level where the new setup of the systems in the room was not 
enough. Also for the evaluation of PMV and PPD parameters, it can be seen that the given setting reduced the mean heat feeling and the percentage of dissatisfied (Fig.7). Subsequently, this setting was also evaluated through interviews with specific employees. Workers felt better conditions at the beginning of the work change, then the changes were no longer clear compared to the original setting. The problem was that the feeling of dissatisfaction in the head area increased due to to the higher air flow rate.

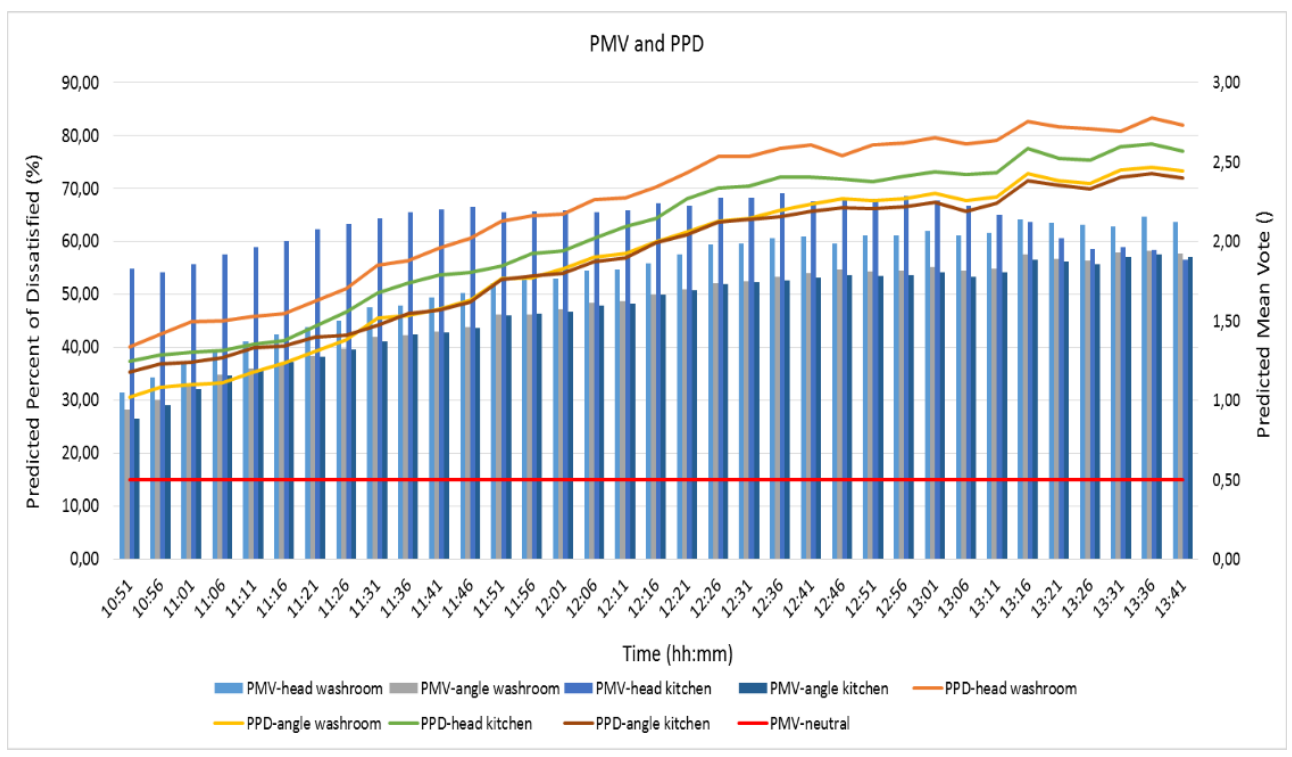

Fig. 7: Parameters PMV and PPD - new settings

\section{Conclusion}

The thermal environment in kitchens and food outlets was evaluated in the summer. This period was defined by the employees on the basis of interviews. It is highly probable that kitchen workers are exposed to an unpleasant thermal environment, especially the feeling of heat. PMV and PPD parameters are at high levels. The applicability of the condition for thermal comfort at the level of PMV +2 was exceeded and for a neutral feeling of +0.5 was not achieved at all. In the next solution, the possibility of application of a suitable air-conditioning device or a change of instrumentation to ensure thermal comfort will be analysed. Subsequently, these changes will be subjected to measurements and the results will be further published. A positive result of these measurements is the fact that working conditions have been improved to a certain extent, which has also been identified by the employees. In solving the issue and research of operating conditions in operation, we will focus on the next period. Our goal is to design an efficient and functional heat dissipation system and to ensure health protection at work. An important factor is compliance with air velocity and eliminate harassment drafts in the space.

\section{Acknowledgements}

"This publication was realized with support of Operational Program Integrated Infrastructure 2014 - 2020 of the project: Innovative Solutions for Propulsion, Power and Safety Components of Transport Vehicles, code ITMS 313011V334, cofinanced by the European Regional Development Fund" and this work was supported by Grant System of University of Zilina No. 8021. 1/2020. 


\section{References}

[1] Simone, A., Olesen, B.W., Stoops, J. "Thermal comfort in commercial kitchens (RP-1469): Procedure and physical measurements (Part 1)," in HVAC\&RESEARCH, Taylor\&Francis, vol. 13, pp. 1001-1015, 2013

[2] Sumei, L., Cao, Q., Zhao, X., Lu, Z., Deng, Z., Dong, J., Lin, X., Qing,K., Zhang, W., Chen, Q. "Improving indoor air quality and thermal comfort in residential kitchens with a new ventilation system," in Building and Environment, vol. 180 , p. 15,2020

[3] Lai, C. "Assessment of side exhaust systems for residential kitchens in Taiwan," Build. Serv. Eng. Technol., 26 (2) (2005), pp. 157-166

[4] Wei, P., Zhou, B., Tan, M., Li, F., Lu, J., Dong.Z., Xu, M., Wang, G., Xiao, Y. "Study on thermal comfort under nonuniform thermal environment condition in domestic kitchen," Procedia Eng., 205 (2017), pp. 2041-2048

[5] Kim, C., Gao, Y.T., Xiang, Y.B. "Home kitchen ventilation, cooking fuels, and lung cancer risk in a prospective cohort of never smoking women in Shanghai, China," Int. J. Canc., 136 (3) (2015), pp. 632-638

[6] Hou, J., Sun, H., Zhou, Y. Zhang, Y., Yin, W., Xu, T, Cheng, J., Chen, W., Yuan, J. "Environmental exposure to polycyclic aromatic hydrocarbons, kitchen ventilation, fractional exhaled nitric oxide, and risk of diabetes among Chinese females," Indoor Air, 28 (3) (2018), pp. 383-393

[7] Dai, W., Zhong, H., Li, L. "Characterization and health risk assessment of airborne pollutants in commercial restaurants in northwestern China: under a low ventilation condition in wintertime," Sci. Total Environ., 633 (2018), pp. 308-316

[8] Alam, Md. S, Muthiah, A., Salve, U.R. "Thermal Comfort Study in Indian Railway Pantry Cars Kitchen," in IIETA, pp. 289-295, https://doi.org/10.18280/i2m.190406

[9] Rahmillah, F.I., Tumanggor, A.H.U., Sari, A.D. "The Analysis of Thermal Comfort in Kitchen," in IOP Conference Series Materials Science and Engineering, MOIME 2017, doi:10.1088/1757-899X/215/1/012033

[10] Schrock, D., Beardslee, D., Sun, Z. "Effect of replacement air systems on kitchen comfort," in Indoor Air 2002, [Online]. Available: https://www.irbnet.de/daten/iconda/CIB7523.pdf

[11] Humphreys, M.A. "Thermal comfort temperatures world-wide - the current position," in Renewable Energy 1996, Volume 8, Issues 1-4, pp. 139-144. [Online]. Available: doi. 10.1016/0960-1481(96)88833-1.

[12] Emmerich, S.; Polidoro, B.; Axley, J. "Impact of adaptive thermal comfort on climatic suitability of natural ventilation of office buildings," in Energy Build 2011, 43, 2101-2107. [Online]. Available: doi: 10.1016/j.enbuild.2011.04.016.

[13] Barlow, S.; Fiala, D. "Occupant comfort in UK offices: how adaptive comfort theories might influence future low energy office refurbishment strategies," in Energy Build 2007, 39, 837-846. [Online] Available: doi:10.1016/j.enbuild.2007.02.002.

[14] Stern, N.; Peters, S.; Bakhshi, V.; Bowen, A.; Cameon, C.; Catovsky, S.; Crane, D.; Cruickshank, S.; Dietz, S.; Edmonson, N.; Garbett, S.-L.; Hamid, L.; Hoffman, G.; Ingram, D.; Jones, B.; Patmore, N.; Radcliffe, H.; Sathiyarajah, R.; Stock, M.; Taylor, C.; Vernon, T.; Wanjie, H.; Zenghelis, D.: Stern review: the economics of climate change. 2006, HM Treasury London. Available online: http://www.hm-treasury.gov. uk/stern_review_report.htm. Accessed July 2011.

[15] ISO 7730. Ergonomics of the Thermal Environment; Ergonomics of the physical environment: Geneva, Switzerland, 2005. Available online: https://www.iso.org/standard/39155.html. Accessed 15. November 2005.

[16] ASHRAE Thermal environmental conditions for human occupancy. ASHRAE Standard 55. 2017, American Society of Heating, Refrigerating and Air-Conditioning Engineers, Atlanta, Georgia, ISSN 1041-2336

[17] Regulation No. 99/2016. Regulation of the Ministry of Health of the Slovak Republic on details on health protection against heat and cold stress at work. [Online] Available: https://www.epi.sk/zz/2016-99

[18] DantecComfortSense. [Online] Available: https://www.dantecdynamics.com/solutions-applications/solutions/thermalcomfort/comfortsense/ 